\title{
Fractional-Order Modeling and Sliding Mode Control of Energy-Saving and Emission- Reduction Dynamic Evolution System
}

\author{
Huang, Sunhua; Zhou, Bin; Li, Canbing; Wu, Qiuwei; Xia, Shiwei; Wang, Huaizhi; Yang, Hanyu
}

Published in:

International Journal of Electrical Power and Energy Systems Engineering

Link to article, DOI:

10.1016/j.ijepes.2018.02.045

Publication date:

2018

Document Version

Publisher's PDF, also known as Version of record

Link back to DTU Orbit

Citation (APA):

Huang, S., Zhou, B., Li, C., Wu, Q., Xia, S., Wang, H., \& Yang, H. (2018). Fractional-Order Modeling and Sliding Mode Control of Energy-Saving and Emission-Reduction Dynamic Evolution System. International Journal of Electrical Power and Energy Systems Engineering, 100, 400-410. https://doi.org/10.1016/j.ijepes.2018.02.045

\section{General rights}

Copyright and moral rights for the publications made accessible in the public portal are retained by the authors and/or other copyright owners and it is a condition of accessing publications that users recognise and abide by the legal requirements associated with these rights.

- Users may download and print one copy of any publication from the public portal for the purpose of private study or research.

- You may not further distribute the material or use it for any profit-making activity or commercial gain

- You may freely distribute the URL identifying the publication in the public portal 


\title{
Fractional-order modeling and sliding mode control of energy-saving and emission-reduction dynamic evolution system
}

\author{
Sunhua Huang ${ }^{\mathrm{a}, \mathrm{b}}$, Bin Zhou ${ }^{\mathrm{a}, \mathrm{b}, *}$, Canbing $\mathrm{Li}^{\mathrm{a}}{ }^{\mathrm{b}}$, Qiuwei $\mathrm{Wu}^{\mathrm{c}}$, Shiwei Xia ${ }^{\mathrm{d}}$, Huaizhi Wang ${ }^{\mathrm{e}}$, \\ Hanyu Yang ${ }^{\mathrm{a}}$

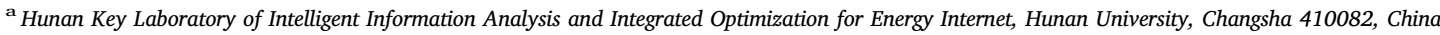 \\ ${ }^{\mathrm{b}}$ College of Electrical and Information Engineering, Hunan University, Changsha 410082, China \\ ${ }^{c}$ Department of Electrical Engineering, Technical University of Denmark, Lyngby 2800, Denmark \\ d School of Electrical and Electronic Engineering, North China Electric Power University, Beijing 102206, China \\ e College of Mechatronics and Control Engineering, Shenzhen University, Shenzhen 518060, China
}

A R T I C L E I N F O

\section{Keywords:}

Energy saving

Emission reduction

Fractional order

Renewable energy

Sliding-mode control

\begin{abstract}
A B S T R A C T
This paper proposes the fractional-order modeling for sliding mode control of a complex four-dimensional energy-saving and emission-reduction system (ESERS). In the proposed methodology, the fractional calculus techniques are employed to accurately model the dynamics of the ESERS, and the fractional-order model of the energy-saving and emission-reduction system (FOESERS) is formulated. With the proposed FOESERS, all of the equilibrium points and the corresponding eigenvalues are obtained, and the instability region and the state trajectories of FOESERS are also given. The FOESERS can represent complex dynamic behaviours with chaotic and unstable states on the energy conservation, carbon emissions, economic growth, and renewable energy development, and have a great impact on the formulation of government energy policies. Furthermore, based on the fractional Lyapunov stability and robust control theory, a sliding-mode controller is designed to control the FOESERS with model uncertainties and external disturbances to the equilibrium point in the finite time. Finally, simulation results confirm the effectiveness and robustness of the proposed scheme.
\end{abstract}

\section{Introduction}

Energy is important for the global economic development and social progress [1]. Economic growth can promote the structural reformation of energy resource exploitation and utilization, and thus further improvements on energy efficiency and energy intensity are expected [2]. However, the rapid economic growth may lead to an increasing energy demand of fossil fuels, and the excessive use of fossil fuel derivatives will result in greenhouse gas emissions (GHG) and environmental pollution issues, especially in developing countries [3-7]. According to the annual time-series data of energy consumption, Gross Domestic Product (GDP) and renewable energy development during 2006-2016 from China National Statistics Yearbook [8,9], the annual GDP of China increased from 3288.3 billion US dollars in 2006 to 11154.4 billion US dollars in 2016, while the total energy consumption grew from 2447.6 million tons coal equivalent (MTCE) in 2006 to about 4360 MTCE in 2016. Also, the overall installed capacity of renewable energy sources in China accounted for $139.9 \mathrm{GW}$ in 2006 and reached about $600 \mathrm{GW}$ in 2016, while the annual carbon emissions totaled 7.2 billion metric tons in 2006 and reached 10.6 billion metric tons in 2016 [9]. With the surge of fossil fuel prices and increasing environment concerns over the years, great pressure to curb the emissions and energy intensity have forced China to implement various energy-saving and emissionreduction measures in order to establish an energy-efficient and environmentally-friendly society for sustainable development $[10,11]$.

The causal relationship exists among energy consumption, $\mathrm{CO}_{2}$ emissions, and economic growth. Lots of work has been done to demonstrate the impacts of carbon emissions and economic growth on energy consumption $[2,5,6,12-16]$. Besides, different mathematical models of energy-saving and emission-reduction system (ESERS) have been developed in [17-20] to simulate the nonlinear coupling dynamics of energy conservation, economic growth, carbon emissions, and renewable energy development in the evolutionary process. The ESERS models can indicate various sophisticated issues, such as energy-saving and emission-reduction, economic growth, carbon emissions, carbon tax, energy intensity, energy efficiency and so on, in a regional energy system $[14,20]$. By analyzing the reciprocal causation of these factors, the improvements on energy efficiency, energy intensity and

\footnotetext{
* Corresponding author at: Hunan Key Laboratory of Intelligent Information Analysis and Integrated Optimization for Energy Internet, Hunan University, Changsha 410082, China.

E-mail address: binzhou@hnu.edu.cn (B. Zhou).
} 
greenhouse gas emissions can be achieved to promote the energy structure transformation and transition to a low-carbon economy $[12,13]$. Most notably, Tian LX et al. proposed a three-dimensional model of the ESERS in [17] considering the complicated relationship between energy-saving and emission-reduction, economic growth and carbon emissions. The quantitative coefficients of the proposed ESERS model were identified based on artificial neural networks in [17], and an empirical study with the statistical data from China confirmed the perfect agreement of the model performance with real-world situations. Furthermore, the renewable energy capacity is taken into account to develop a new four-dimensional ESERS model in [18]. The ESERS is a complex oscillatory system and exhibits highly nonlinear characteristics with aperiodic, sudden, or random phenomena. Hence, the stabilization of the ESERS is of a major strategic significance for ensuring economic development, reducing energy security and maintaining environment sustainability, and it is important to develop robust control methodologies for supporting the ESERS with uncertainties and external disturbances.

Because of the high nonlinear complexity of the ESERS, the dynamic behaviours of ESERS have been investigated in $[17,18]$ by the equilibrium points and Lyapunov exponents. Various stability control methods, including linear feedback control [18] and impulsive control [21], have been applied to suppress system chaos for stable equilibrium. The previous modeling and control methods of ESERS in [17-21] are based on the integer-order model. However, the state variables of the ESERS have hereditary properties with long-memory effects, and the evolutionary dynamics of the ESERS are often better described by fractional derivatives due to its global correlation characteristics $[22,23]$. Thus, the fractional calculus can extend the integer-order calculus models to the non-integer order models [24], and is proven to be a very suitable and flexible tool to characterize the genetic memory properties in various chaotic evolutionary processes [23-28]. So far, many practical nonlinear systems in electrical energy fields [27-34], such as the energy supply-demand system [27], hydro-turbine governing system [29], and wind turbine [31], have been modelled using fractional differential equations. This paper aims to investigate the modeling and control of the fractionalorder energy-saving and emission-reduction system (FOESERS) to coordinate the dynamic performance of energy conservation, economic growth, carbon emissions, and renewable energy development.

In this paper, the fractional integrals and derivatives are used to present the complex dynamics of ESERS, and the FOESERS model can be formulated based on fractional order calculus. The fractional differential equations of the ESERS are thoroughly investigated to solve the equilibrium points and their corresponding eigenvalues, and the instability region and the state trajectories of the FOESERS are also given. Numerical simulations on the dynamic behaviours of FOESERS indicate the nonlinear chaotic and unstable phenomena on energy conservation, economic growth, carbon emissions, and renewable energy development. Hence, based on the fractional Lyapunov stability theory and sliding mode control theory, a robust control method is designed to stabilize the FOESERS with model uncertainties and external disturbances to the equilibrium point in a finite time. Comparative results on a practical system with different fractional orders as well as different uncertainty and external disturbances confirm the effectiveness and robustness of the proposed control scheme.

The rest of this paper is organized as follows: The mathematical modeling of a FOESERS with its dynamic behaviours is formulated and investigated in Section 2. In order to enhance the stability of FOESERS, a robust fractional-order finite-time controller based on sliding mode control theory is designed in Section 3. Three illustrative examples are provided in Section 4. Finally, Section 5 concludes this paper.

\section{Fractional-order modeling of ESERS}

\subsection{Integer-order model of ESERS}

The dynamic evolution model of ESERS can be formulated as the following mathematical form [18],

$\left\{\begin{array}{l}\dot{x}_{1}=\alpha_{1} x_{1}\left(\frac{x_{2}}{N}-1\right)-\alpha_{2} x_{2}+\alpha_{3} x_{3} \\ \dot{x}_{2}=-\beta_{1} x_{1}+\beta_{2} x_{2}\left(1-\frac{x_{2}}{K}\right)+\beta_{3} x_{3}\left(1-\frac{x_{3}}{L}\right)-\delta_{4} x_{4} \\ \dot{x}_{3}=\gamma_{1} x_{1}\left(\frac{x_{1}}{M}-1\right)-\gamma_{2} x_{2}-\gamma_{3} x_{3}+\gamma_{4} x_{4}\left(\frac{x_{4}}{E}-1\right) \\ \dot{x}_{4}=\delta_{1} x_{2}+\delta_{2} x_{3}\left(\frac{x_{3}}{C}-1\right)-\delta_{3} x_{4}\end{array}\right.$

where $x_{1}$ is the variable of energy saving, typically expressed in MTCE; $x_{2}$ is a variable of carbon emissions, typically expressed in ton; $x_{3}$ is a variable of economic growth GDP, typically expressed in US dollar; $x_{4}$ is a variable of renewable energy development in a given period, typically expressed in GW. $\alpha_{i}, \beta_{i}, \gamma_{j}, \delta_{j}, M, N, C, E$ are positive constants $(i=1,2$, $3, j=1,2,3,4)$, and the units of $M, N, C, E$ can be converted to tons of standard coal). $\alpha_{1}$ is the development factor of $x_{1} ; \alpha_{2}$ is the impact factor of $x_{2}$ to $x_{1} ; \alpha_{3}$ is the impact factor of $x_{3}$ to $x_{1} ; N$ is the inflexion (local maximum point) of $x_{2}$ to $x_{1} ; \beta_{1}$ is the impact factor of $x_{1}$ to $x_{2} ; \beta_{2}$ is the development factor of $x_{2} ; \beta_{3}$ is the impact factor of $x_{3}$ to $x_{2} ; K$ is the crest value of $x_{2}$ in a given period; $L$ is the crest value of $x_{3}$ in a given period; $\delta_{4}$ is the impact factor of $x_{4}$ to $x_{2} ; \gamma_{1}$ is the impact factor of $x_{1}$ to $x_{3} ; \gamma_{2}$ is the impact factor of $x_{2}$ to $x_{3} ; \gamma_{3}$ is the impact factor to itself; $M$ is the inflexion of $x_{1}$ to $x_{3} ; \gamma_{4}$ is the impact factor of $x_{4}$ to $x_{3}$, and $E$ is the inflexion of $x_{4}$ to $x_{3} ; \delta_{1}$ is the impact factor of $x_{2}$ to $x_{4} ; \delta_{2}$ is the impact factor of $x_{3}$ to $x_{4} ; C$ is the inflexion of $x_{3}$ to $x_{4}$, and $\delta_{3}$ is the impact factor to itself [18].

Based on the normalization of the ESERS from the statistical data in China $[8,9]$, the impact factors of the system can be obtained by the parameter identification using artificial neural network in $[17,18]$. Hence, the model parameters are set as follows: $\alpha_{1}=0.09$, $\beta_{1}=0.0412, \quad \gamma_{1}=0.035, \quad \delta_{1}=0.01, \quad \alpha_{2}=0.003, \quad \beta_{2}=0.08$, $\gamma_{2}=0.0062, \delta_{2}=0.02, \alpha_{3}=0.012, \beta_{3}=0.8, \gamma_{3}=0.08, \delta_{3}=0.06$, $\gamma_{4}=0.02, \quad \delta_{4}=0.03, \quad M=3.5, \quad E=2, \quad C=2, \quad K=1.6, \quad N=0.9$, $L=2.8$.

\subsection{Fractional-order model of ESERS}

In this subsection, the definitions of fractional-order derivatives and the lemmas on fractional order system are provided. Then, following the integer-order model of the ESERS in Eq. (1), the fractional-order model of the ESERS can be formulated based on the fractional-order differential equations.

Definition 1 ([26]). The definition of Caputo fractional-order derivative is described by,

${ }_{t_{0}}^{C} D_{t}^{q} x(t)= \begin{cases}\frac{1}{\Gamma(n-q)} \int_{t_{0}}^{t} \frac{x^{n}(\tau)}{(t-\tau)^{q+1-n}} d \tau & n-1<q<n \\ \frac{d^{n} x(t)}{d t^{n}} & q=n\end{cases}$

where $q$ is the fractional order of the system, and $\Gamma(\cdot)$ which is defined as $\Gamma(\tau)=\int_{0}^{\infty} t^{\tau-1} e^{-t} d t$ is the gamma function.

Definition 2 ([24]). The definition of Riemann-Liouville fractionalorder derivative is described by,

${ }_{R L} D_{t_{0}, t}^{q} x(t)=\frac{1}{\Gamma(n-q)} \frac{d^{n}}{d t^{n}} \int_{t_{0}}^{t}(t-\tau)^{n-q-1} x(\tau) d \tau \quad n-1<q<n$

Definition 3 ([24]). The Laplace transform of the Caputo fractionalorder derivative is described by, 
$\ell\left\{{ }_{t_{0}}^{C} D_{t}^{q} x(t)\right\}=s^{q} X(s)-\sum_{k=0}^{n-1} s^{q-k-1} x^{(k)}\left(t_{0}\right) \quad n-1<q<n$

where $X(s)$ is the Laplace transform of $x(t)$.

Definition 4 ([24]). The Laplace transform of Riemann-Liouville fractional-order derivative is described by,

$\ell\left\{{ }_{R L} D_{t_{0}, t}^{q} x(t)\right\}=s^{q} X(s)-\sum_{k=0}^{n-1} s^{k}\left[D^{q-k-1} x(t)\right]_{t=t_{0}} \quad n-1<q<n$

Lemma 1 ([27]). Considering the fractional commensurate order system $D^{q_{i} x}=f(x), q_{1}=q_{2}=\cdots=q_{i}$, where $0<q_{i} \leqslant 1$, if all eigenvalues which are evaluated at the equilibrium points of the Jacobian matrix $J=\partial f / \partial x$ satisfy $\left|\arg \left(\lambda_{i}\right)\right|>q \pi / 2$, the system is asymptotic stability.

Lemma 2 ([33]). Considering the fractional incommensurate order system $D^{q_{i} x}=f(x), q_{1} \neq q_{2} \neq \cdots \neq q_{n}$, where all $q_{i}$ are the orders of the fractional incommensurate order system between 0 and 1 , the equilibrium point $x=x_{*}$ for the system is asymptotically stable if,

$\left|\arg \left(\lambda_{i}\right)\right|>\pi /(2 H)$

where $\lambda_{i}$ are the roots of the following equation,

$\operatorname{det}\left(\operatorname{diag}\left(\left[\begin{array}{lll}\lambda^{H q_{1}} & \lambda^{H q_{2}} & \cdots \lambda^{H q_{n}}\end{array}\right]\right)-J^{*}\right)=0$

where $J^{*}=\frac{\partial f}{\partial x} \mid x_{*} ; f=\left[f_{1}, f_{2} \cdots, f_{n}\right]^{\mathrm{T}} ; q_{i}=v_{i} / \mu_{i} ; H$ is the least common multiple of the denominators $\mu_{i}$ of $q_{i}$; The greatest common divisor of $\mu_{i}$ and $v_{i}$ is 1 , i.e. $\left(\mu_{i}, \nu_{i}\right)=1 ; \mu_{i}, \nu_{i} \in Z^{+}, i=1,2, \cdots, n$.

Property 1 ([35]). The following equality for the Caputo derivative and the Riemann-Liouville derivative is hold:

${ }^{R L, C} D^{\alpha}\left({ }^{R L, C} D^{-\beta} f(x(t))\right)={ }^{R L, C} D^{\alpha-\beta} f(x(t))$

From the Caputo definition and Riemann-Liouville definition in Eqs. (2) and (3), it can be found that the Laplace transform of RiemannLiouville definition in Eq. (5) includes the fractional-order derivative terms, while the Laplace transform of Caputo definition in Eq. (4) contains integer-order derivative terms which formulate the fractionalorder differential equations with clear physical interpretations. Moreover, the Caputo fractional-order derivative has the widely spread application in the actual modeling process [35]. Hence, the Caputo definition is considered in this paper to characterize the genetic memory properties of energy saving, carbon emissions, GDP, and renewable energy development. Here, $D^{q}$ represents the Caputo derivative with fractional order $q$. Inspired from [33] and the ESERS in Eq. (1), the dynamic model of the FOESERS can be formulated as follows,

$\left\{\begin{array}{l}D^{q_{1} x_{1}}=\alpha_{1} x_{1}\left(\frac{x_{2}}{N}-1\right)-\alpha_{2} x_{2}+\alpha_{3} x_{3} \\ D^{q_{2}} x_{2}=-\beta_{1} x_{1}+\beta_{2} x_{2}\left(1-\frac{x_{2}}{K}\right)+\beta_{3} x_{3}\left(1-\frac{x_{3}}{L}\right)-\delta_{4} x_{4} \\ D^{q_{3}} x_{3}=\gamma_{1} x_{1}\left(\frac{x_{1}}{M}-1\right)-\gamma_{2} x_{2}-\gamma_{3} x_{3}+\gamma_{4} x_{4}\left(\frac{x_{4}}{E}-1\right) \\ D^{q_{4}} x_{4}=\delta_{1} x_{2}+\delta_{2} x_{3}\left(\frac{x_{3}}{C}-1\right)-\delta_{3} x_{4}\end{array}\right.$

In the first formula in Eq. (9), $D^{q}{ }_{1} x_{1}$ is the fractional-order form of $d x_{1} / d t$. The first formula in Eq. (9) indicates the complex relationship between the variables of carbon emissions and emission reduction $D^{q}{ }_{1} x_{1}$, carbon emissions, energy conservation and economic growth in a given period, and it demonstrates that the variation of energy saving and emission reduction with time $D^{q}{ }_{1} x_{1}$ is connected to the amount of energy saving $x_{1}$ and the share of energy saving and emission reduction potential $x_{2} / N-1$ simultaneously. As for $\alpha_{1} x_{1}\left(x_{2} / N-1\right)$, when $x_{2}<N$, i.e., $x_{2} / N-1<0$, the growth speed of $x_{1}$ becomes slower; when $x_{2}>N$, the growth speed of $x_{1}$ becomes faster. $D^{q}{ }_{1} x_{1}$ is proportional to economic growth $x_{3}$, but it is inversely proportional to carbon emissions $x_{2}$. $D^{q}{ }_{1} x_{1}$ will increase as the investment in $x_{1}$ increase [17].
In the second formula in Eq. (9), $D^{q}{ }_{2} x_{2}$ is the fractional-order form of $d x_{2} / d t$. The second formula in Eq. (9) shows that the variation of carbon emissions $D^{q}{ }_{2} x_{2}$ that changes with time is proportional to $x_{1}$, and the increment of $x_{1}$ will slow down the change rate of $D_{2}^{q} x_{2}$. The growth trend of $x_{2}$ is fast before the peak value $K$ and slows down after the peak value. The initial stage of development of $x_{3}$ will result in substantial carbon emissions, and its effects on $x_{2}$ will trend to be moderate after the peak value $L$. As for $\beta_{2} x_{2}\left(1-x_{2} / K\right)$, when $x_{2}<K$, i.e., $1-x_{2} / K>0$, the growth speed of $x_{2}$ will be fast; when $x_{2}>K$, the growth trend of $x_{2}$ slows down. As for $\beta_{3} x_{3}\left(1-x_{3} / L\right)$, when $x_{3}<L$, then $1-x_{3} / L>0$, the effects of $x_{3}$ for $x_{2}$ is positive; $x_{3}$ will has negative effects on $x_{2}$ will be negative when $x_{3}$ reaches the peak value $L . D_{2}^{q} x_{2}$ is inversely proportional to renewable energy development $x_{4}$, and the addition of $x_{4}$ will offset the change rate of $D^{q}{ }_{2} x_{2}$.

In the third formula in Eq. (9), $D^{q}{ }_{3} x_{3}$ is the fractional-order form of $d x_{3} / d t$. The third formula in Eq. (9) reveals that the early investment of $x_{1}$ will offset the growth of $x_{3}$. With the improvement of the energy saving and emission reduction technology for $x_{1}, x_{1}$ will further promote the development of $x_{3}$. As for $\gamma_{1} x_{1}\left(x_{1} / M-1\right)$, when $x_{1}<M$, i.e., $x_{1} / M-1<0, x_{1}$ has a negative effect on $x_{3}$; when $x_{1}>M$, the effect of $x_{1}$ on $x_{3}$ is positive. The change of economic growth with time $D^{q} x_{3}$ is inversely proportional to $x_{2}$, and thus the addition of $x_{2}$ will offset the development of $x_{3} . D^{q} x_{3}$ is inversely proportional to investment for energy-saving and emission-reduction, and the investment will offset the growth of $x_{3}$ in a certain degree. The initial investment in $x_{4}$ will offset the development of $x_{3}$. With the advancement of $x_{4}, x_{4}$ will boost $x_{3}$ in turn. As for $\gamma_{4} x_{4}\left(x_{4} / E-1\right)$, when $x_{4}<E$, i.e., $x_{4} / E-1<0, x_{4}$ has a positive effect on $x_{3}$; when $x_{4}>E$, the effect of $x_{4}$ on $x_{3}$ is positive.

In the fourth formula in Eq. (9), $D^{q}{ }_{4} x_{4}$ is the fractional-order form of $d x_{4} / d t$. The fourth formula in Eq. (9) indicates that $D^{q}{ }_{4} x_{4}$ is positively proportional to carbon emissions $x_{2}$, and this means that the increase of carbon emissions will enhance the growth of $D_{4}^{q} x_{4}$. The low level of $x_{3}$ will also offset the development of $x_{4}$. With the growth of $x_{3}, x_{3}$ will promote the value of $x_{4}$. As for $\delta_{2} x_{3}\left(x_{3} / C-1\right)$, when $x_{3}<C$, i.e., $x_{3} / C-1<0$, the effect of $x_{3}$ on $x_{4}$ is negative. The change of renewable energy development $D_{4}^{q} x_{4}$ with time-dependent is inversely proportional to $x_{4}$, and $D_{4}^{q} x_{4}$ will decrease as $x_{4}$ increases [18].

\subsection{Dynamic properties of FOESERS}

In this subsection, the properties of the FOESERS model are discussed, including dissipation, equilibrium points and chaos.

\subsubsection{Dissipation}

On evaluating the dissipative nature of the FOESERS, it is found from Eq. (10) that the volume element $V_{0}$ goes on contracting ex-

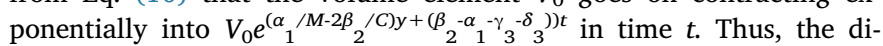
vergence flow of Eq. (10) is dissipative if and only if $\nabla V<0$, i.e.

$$
\begin{aligned}
\nabla V & =\frac{\partial \dot{x}_{1}}{\partial x_{1}}+\frac{\partial \dot{x}_{2}}{\partial x_{2}}+\frac{\partial \dot{x}_{3}}{\partial x_{3}}+\frac{\partial \dot{x}_{4}}{\partial x_{4}}=\frac{\alpha_{1} x_{2}}{N}-\alpha_{1}+\beta_{2}-\frac{2 \beta_{2} x_{2}}{K}-\gamma_{3}-\delta_{3} \\
& =\left(\frac{\alpha_{1}}{N}-\frac{2 \beta_{2}}{K}\right) y+\left(\beta_{2}-\alpha_{1}-\gamma_{3}-\delta_{3}\right)
\end{aligned}
$$

when $\frac{\alpha_{1}}{N}=\frac{2 \beta_{2}}{K}, \beta_{2}-\alpha_{1}-\gamma_{3}-\delta_{3}<0$, the FOESERS system is dissipative.

\subsubsection{Equilibrium points}

The Jacobian matrix can be obtained to study the nonlinear characteristics of FOESERS [18], as follows,

$$
J=\left[\begin{array}{cccc}
\frac{\alpha_{1} x_{2}}{N}-\alpha_{1} & \frac{\alpha_{1} x_{1}}{N}-\alpha_{2} & \alpha_{3} & 0 \\
-\beta_{1} & \beta_{2}-\frac{2 \beta_{2} x_{2}}{K} & \beta_{3}-\frac{2 \beta_{3} x_{3}}{L} & -\delta_{4} \\
\frac{2 \gamma_{1} x_{1}}{M}-\gamma_{1} & -\gamma_{2} & -\gamma_{3} & \frac{2 \gamma_{4} x_{4}}{E}-\gamma_{4} \\
0 & \delta_{1} & \frac{2 \delta_{2} x_{3}}{C}-\delta_{2} & -\delta_{3}
\end{array}\right]
$$

The dynamic characteristics of the FOESERS can be analyzed by the 
Table 1

Equilibrium points and eigenvalues.

\begin{tabular}{ll}
\hline Equilibrium points & The corresponding eigenvalues \\
\hline$E_{1}=(0,0,0,0)$ & $\lambda_{1}=-0.0103, \lambda_{2}=0.0380, \lambda_{3}=-0.0899+0.0216 i, \lambda_{4}=-0.0899-0.0216 i$ \\
$E_{2}=(1.3748,0.7691,1.6915,0.412)$ & $\lambda_{1}=-0.1516, \lambda_{2}=-0.0644, \lambda_{3}=-0.0330+0.2482 i, \lambda_{4}=0.0330-0.2482 i$ \\
$E_{3}=(0.8733,0.8609,0.4999,0.0185)$ & $\lambda_{1}=0.0691, \lambda_{2}=-0.0634, \lambda_{3}=-0.0778+0.2044 i, \lambda_{4}=-0.0778-0.2044 i$ \\
$E_{4}=(-1.5441,1.1453,3.4423,1.0183)$ & $\lambda_{1}=-0.4812, \lambda_{2}=-0.0613, \lambda_{3}=-0.1963+0.2874 i, \lambda_{4}=0.1963-0.2841 i$ \\
\hline
\end{tabular}

eigenvalues which are determined by the Jacobian matrix at the equilibrium point. Set $\quad d^{q_{1}} x_{1} / d t^{q_{1}}=0, d^{q_{2}} x_{2} / d t^{q_{2}}=0, d^{q_{3}} x_{3} / d t^{q_{3}}=$ $0, d^{q_{4}} x_{4} / d t^{q_{4}}=0$, the equilibrium points of FOESERS are obtained. Based on the equilibrium points, the eigenvalues of the Jacobian matrix of the system in Eq. (9) are determined. The Equilibrium points and the corresponding eigenvalues are listed in Table 1.

\subsubsection{Investigation of chaos}

In this subsection, the chaos of the commensurate-order FOESERS and incommensurate-order FOESERS are investigated.

(i) For the commensurate-order FOESERS (i.e. $q_{1}=q_{2}=\cdots=q_{n}$ ), the instability region can be determined based on Lemma 1 by the following condition,

$q \frac{\pi}{2}>\max _{i}\left\{\arg \left|\lambda_{i}\right|\right\}=\max _{i}\left\{\arctan \frac{\left|\operatorname{Im}\left(\lambda_{i}\right)\right|}{\left|\operatorname{Re}\left(\lambda_{i}\right)\right|}\right\}=\arctan \frac{0.2482}{0.0330}$

$$
\rightarrow q>0.9158
$$

Therefore, the necessary condition of instability is $q>0.9158$. Chaotic vibrations in the commensurate-order FOESERS with $q=0.95$ and $q=0.99$, and the state trajectories in the commensurateorder FOESERS with $q=0.95$ and $q=0.99$ are shown in Figs. $1-4$. It is observed that the commensurate-order FOESERS with $q=0.95$ and $q=0.99$ can generate complex chaotic attractors and have
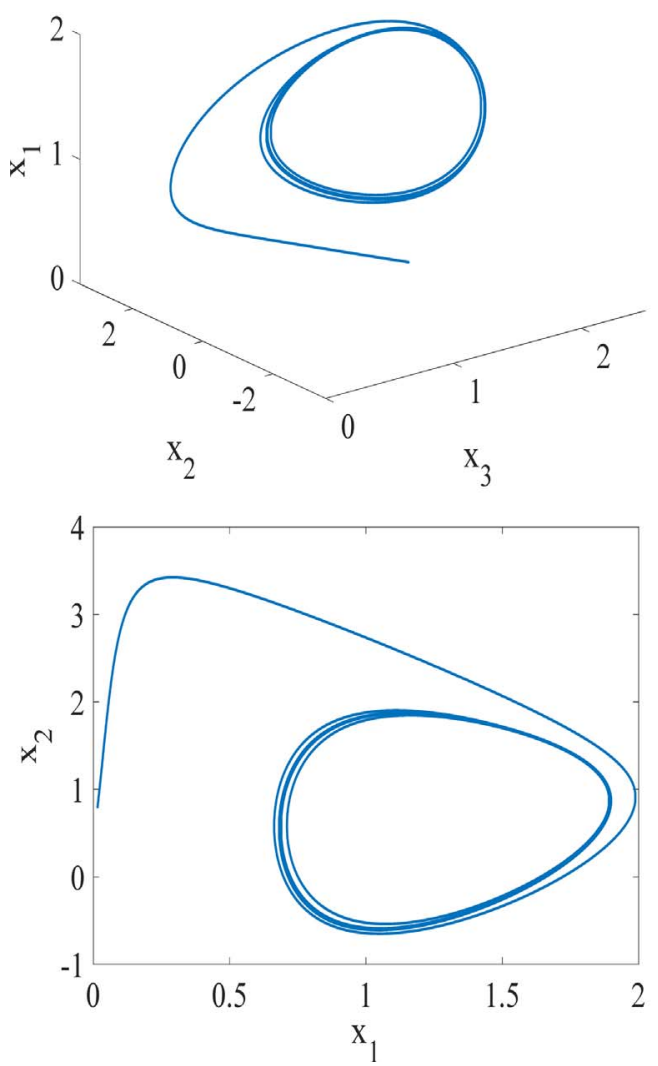

aperiodic, sudden, random, or oscillations. It can also be proved from Figs. 1-4 that the instability region calculated in Eq. (12) turns out to be accurate and correct.

(ii) For the incommensurate-order FOESERS (i.e. $q_{1} \neq q_{2} \neq \cdots \neq q_{n}$ ), the incommensurate order and the equilibrium point are set as $\left(q_{1}, q_{2}, q_{3}, q_{4}\right)=(0.92,0.94,0.96,0.98)$ and $O=(0,0,0,0)$, respectively. Then, the Jacobian matrix can be obtained based on Eq. (11), as follows,

$J^{*}=\left[\begin{array}{cccc}-\alpha_{1} & -\alpha_{2} & \alpha_{3} & 0 \\ -\beta_{1} & \beta_{2} & \beta_{3} & -\delta_{4} \\ -\gamma_{1} & -\gamma_{2} & -\gamma_{3} & -\gamma_{4} \\ 0 & \delta_{1} & -\delta_{2} & -\delta_{3}\end{array}\right]=\left[\begin{array}{cccc}-0.09 & -0.003 & 0.012 & 0 \\ -0.0412 & 0.08 & 0.8 & -0.03 \\ -0.035 & -0.0062 & -0.08 & -0.02 \\ 0 & 0.01 & -0.02 & -0.06\end{array}\right]$

Due to the fractional form $\left(q_{1}, q_{2}, q_{3}, q_{4}\right)=(23 / 25,47 / 50,24 / 25$, 49/50), $H$ is set to be 50 based on Lemma 2. $J^{*}$ and $H=50$ are taken into Eq. (7) in Lemma 2, and Eq. (14) is obtained as,

$$
\begin{aligned}
\lambda^{190} & +0.09 \lambda^{144}-0.08 \lambda^{143}+0.08 \lambda^{142}+0.06 \lambda^{141}-0.00844 \lambda^{97}+0.00678 \lambda^{96} \\
& +0.00396 \lambda^{95}-0.0045 \lambda^{94}+0.0044 \lambda^{93}-0.000248 \lambda^{49}-4.7916 \times 10^{-4} \lambda^{48} \\
& +3.708 \times 10^{-4} \lambda^{47}+4.212 \times 10^{-4} \lambda^{46}+1.3332 \times 10^{-4}=0
\end{aligned}
$$

Then, the roots of Eq. (14) are taken into Eq. (6) and the following can be obtained,
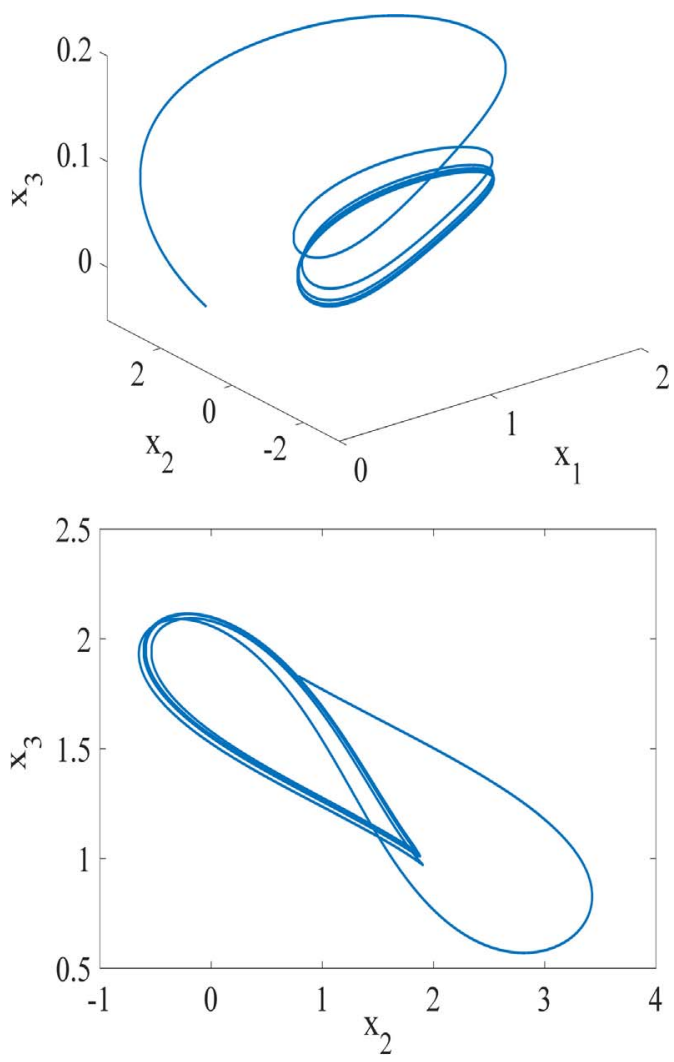

Fig. 1. Chaotic vibration in the commensurate-order FOESERS with $q=0.95$. 

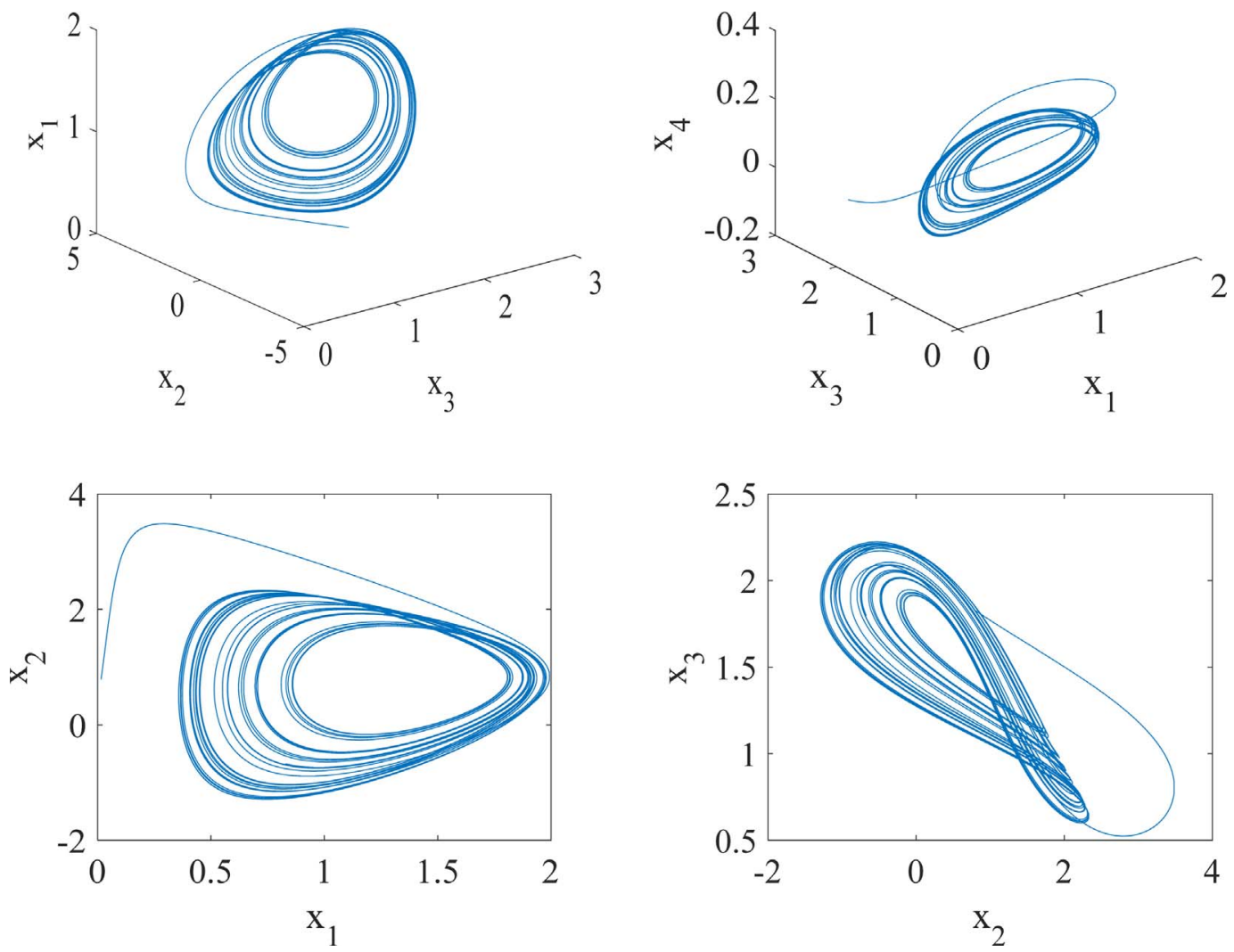

Fig. 2. Chaotic vibration in the commensurate-order FOESERS with $q=0.99$.
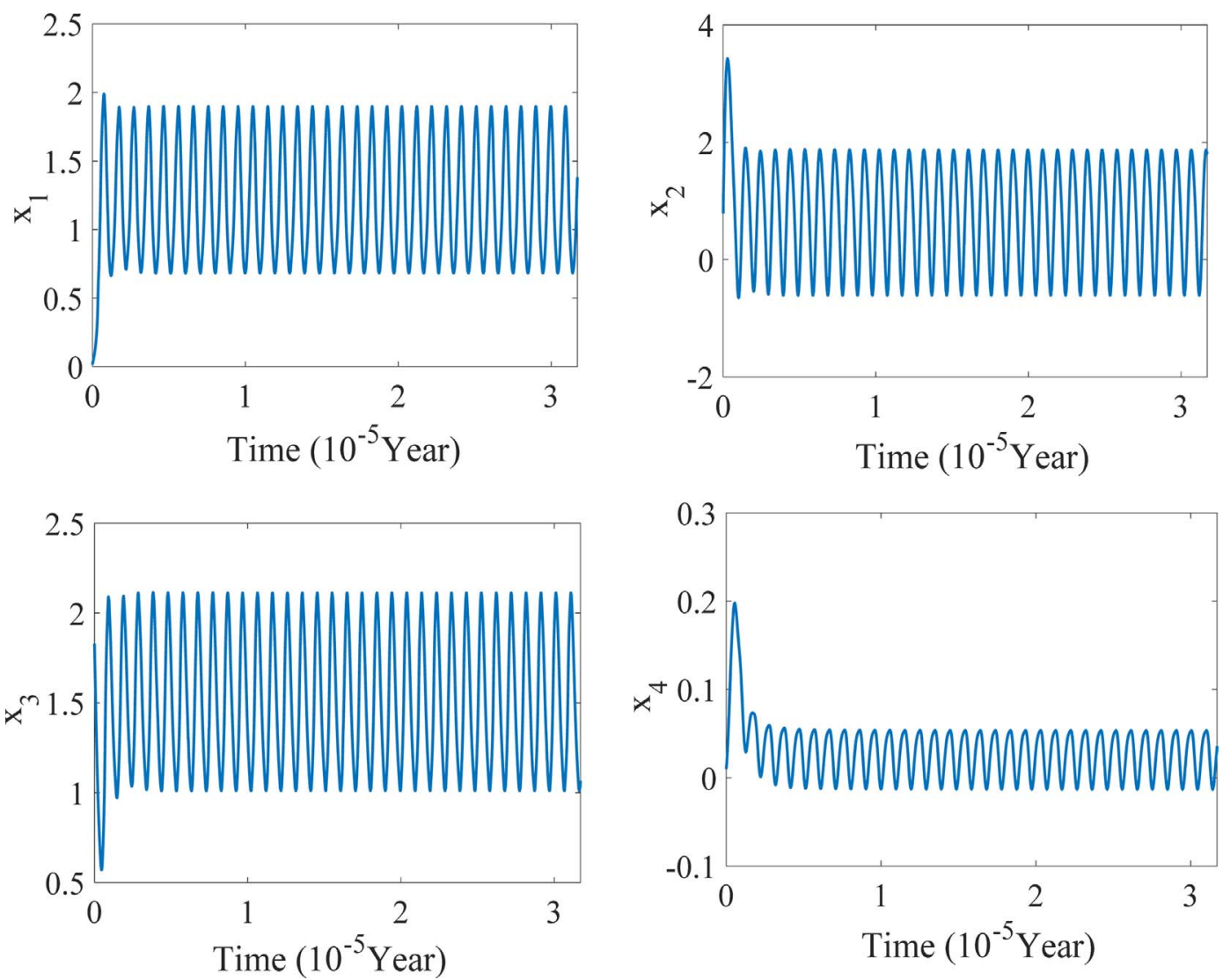

Fig. 3. State trajectories in the commensurate-order FOESERS with $q=0.95$. 

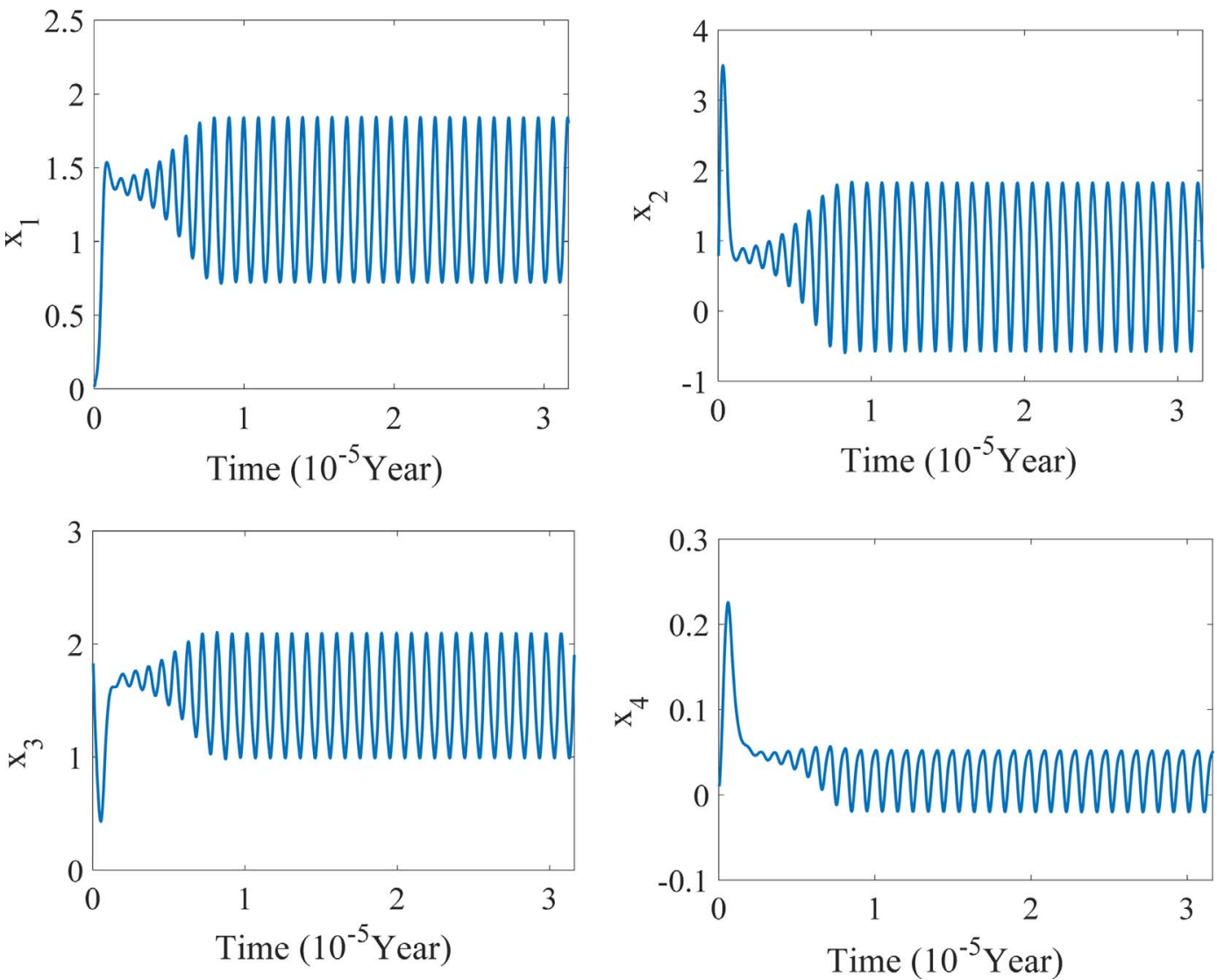

Fig. 4. State trajectories in the commensurate-order FOESERS with $q=0.99$.

$0.01 \pi-\min _{i}\left\{\operatorname{larg}\left(\lambda_{i}\right) \mid\right\}=0.0033>0$

This implies that for derivative orders $\left(q_{1}, q_{2}, q_{3}, q_{4}\right)=$ $(0.92,0.94,0.96,0.98)$, the incommensurate-order FOESERS appears to be aperiodic, sudden, random, or oscillations. Chaotic vibration and state trajectories are shown in Figs. 5 and 6. From the above discussions, the commensurate-order FOESERS and incommensurate-order FOESERS have chaotic and nonlinear phenomena on energy conservation, carbon emissions, economic growth, and renewable energy development. Therefore, it is indispensable to study the stabilization of the chaotic FOESERS.

\section{Design of sliding mode control for FOESERS}

In the practical applications, the dynamics of nonlinear systems should be described using the model with uncertain terms and external disturbances. Hence, the uncertain FOESERS with control inputs is taken into account and the FOESERS with uncertain terms and external disturbances can be formulated as follows,

$D^{q} x(t)=f(x, t)+\Delta f(x, t)+d(t)+u(t)$

where $q \in(0,1]$ is the fractional order coefficient, $x=\left[x_{1}, x_{2}, \cdots, x_{n}\right]^{T}$ represents the state vector of the FOESERS, and $f(x, t)=\left[f\left(x_{1}, t\right), f\left(x_{2}, t\right), \cdots, f\left(x_{n}, t\right)\right]^{T} \in R^{n} \quad$ denotes the nonlinear function; $\quad d(t)=\left[d_{1}(t), d_{2}(t), \cdots, d_{n}(t)\right]^{T} \in R^{n} \quad$ and $\quad \Delta f(x, t)=$ $\left[\Delta f\left(x_{1}, t\right), \Delta f\left(x_{2}, t\right), \cdots, \Delta f\left(x_{n}, t\right)\right]^{T} \in R^{n}$ represent the external disturbance and unknown model with uncertain terms of the system, respectively. $u(t)=\left[u_{1}(t), u_{2}(t), \cdots, u_{n}(t)\right]^{T} \in R^{n}$ is the designed controller.

In this paper, a fractional-order sliding mode controller is designed to stabilize the FOESERS based on the sliding mode control theory. The sliding mode control is to design a controller to impel the system state trajectories to the predetermined sliding mode surface, and the design of sliding mode controller consists of two steps [23]. The first stage is to form a sliding mode surface, meanwhile, the design of the sliding surface is asymptotically stable. The second stage is to design a switch control law to force the trajectories to achieve the sliding surface and remain on it all the time.

The fractional-order sliding surface is given as follows [35],

$s(t)=D^{q-1} x+D^{-1}\left(k_{1} x+k_{2}|x|^{\sigma} \operatorname{sat}(x)\right)$

where $s(t)=\left[s_{1}, s_{2}, \cdots, s_{n}\right]^{\mathrm{T}} \in R^{n}$ are the sliding surfaces; sat( $(\cdot)$ is the saturation function; $k_{1}, k_{2}, \gamma$ are the given parameters, with $k_{1}>0, k_{2}>0,0<\sigma<1$.

The saturation function is given below [35],

$\operatorname{sat}(\vartheta)= \begin{cases}\operatorname{sign}(\vartheta / k), & |\vartheta|>k, k>0 \\ \vartheta / k, & |\vartheta| \leqslant k, k>0\end{cases}$

When the system trajectories reach the sliding surface in Eq. (17), the following equations can be obtained as follows,

$s(t)=0 \quad$ and $\quad \dot{s}(t)=0$

Based on Eq. (17), Eq. (19) and Property 1, the dynamics of the sliding surface can be achieved as follows,

$\dot{s}(t)=D^{q} x+\left(k_{1} x+k_{2}|x|^{\sigma} \operatorname{sat}(x)\right)=0$

The sliding mode dynamic system is obtained as follows,

$D^{q} x=-\left(k_{1} x+k_{2}|x|^{\sigma} \operatorname{sat}(x)\right)$

This implies that fractional-order sliding surface Eq. (17) will converge to zero if and only if Eq. (21) is stable.

In order to demonstrate that the fractional-order sliding surface is stable and the proposed fractional-order controller is robust and effective for the system in Eq. (16), the Lyapunov stability lemmas are introduced, as follows,

Lemma 3 ([27]). If $x=0$ is an equilibrium point for the fractional-order 

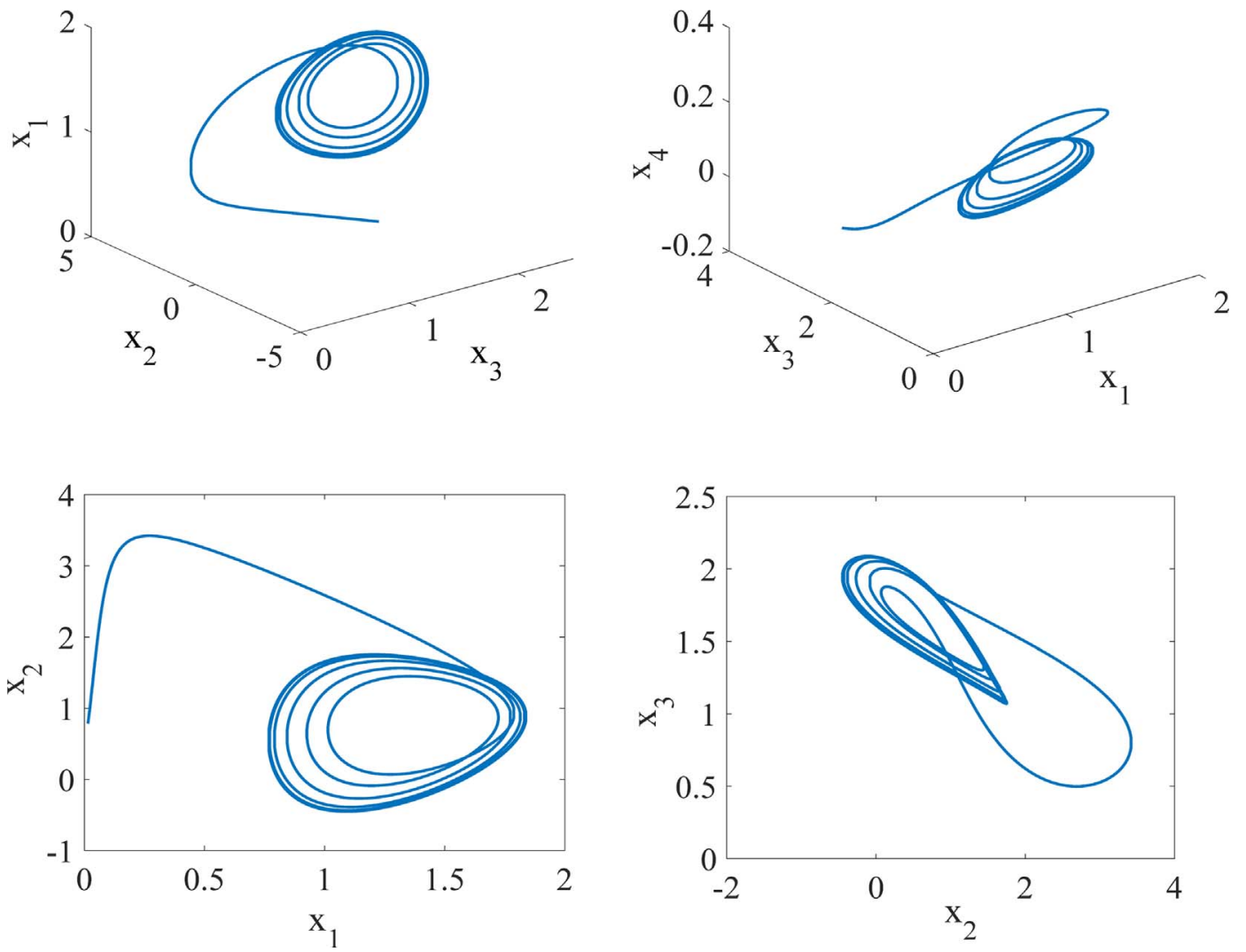

Fig. 5. Chaotic vibration in the incommensurate-order FOESERS with $\left(q_{1}, q_{2}, q_{3}, q_{4}\right)=(0.92,0.94,0.96,0.98)$.
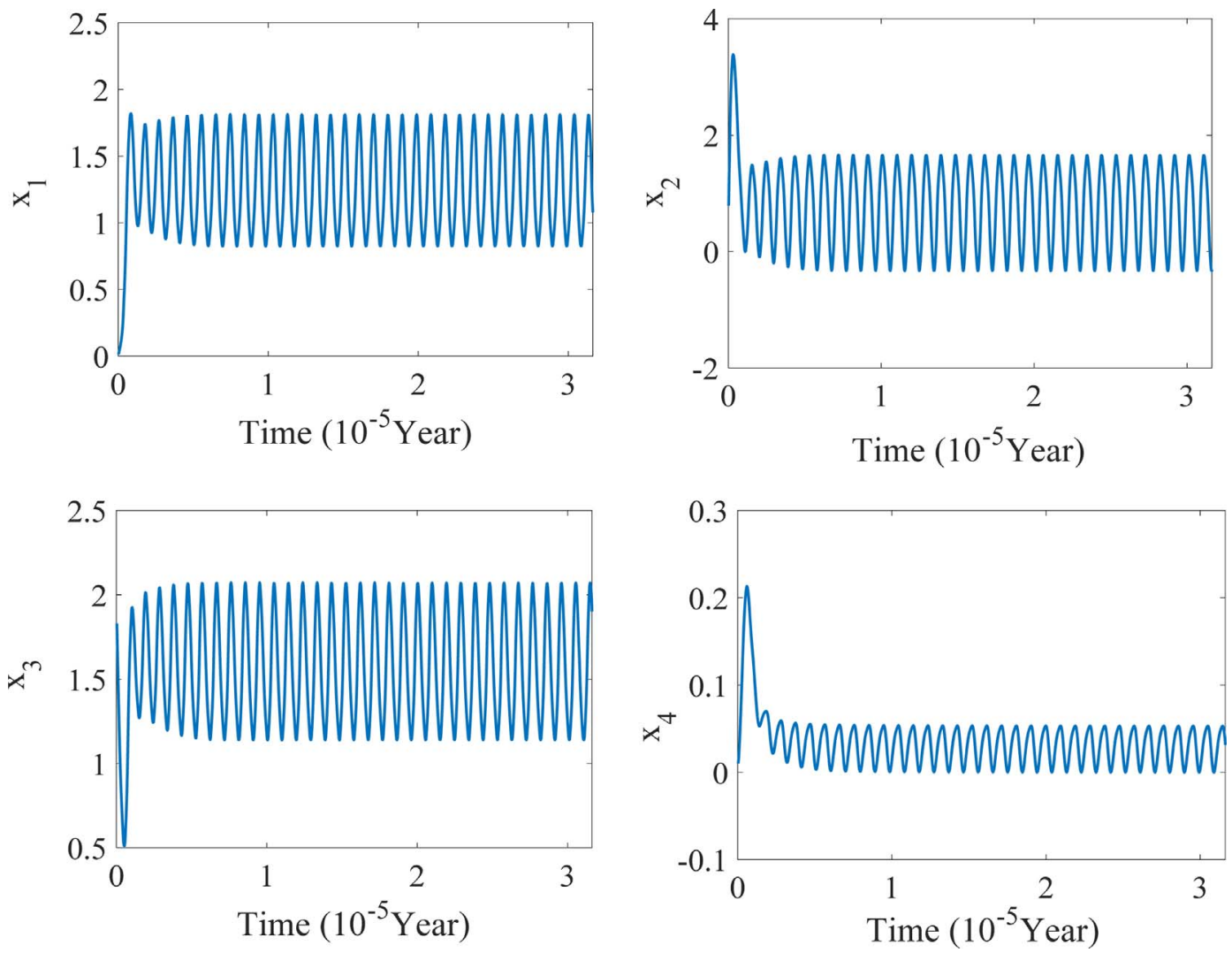

Fig. 6. State trajectories in the incommensurate-order FOESERS with $\left(q_{1}, q_{2}, q_{3}, q_{4}\right)=(0.92,0.94,0.96,0.98)$. 
system $D^{q}=f(x, t)$, and $f(x, t)$ satisfies the Lipschitz condition with the Lipschitz constant $l>0, q \in(0,1]$. There exists a Lyapunov function $V(t,(x, t))$ satisfying the following conditions, and the system is asymptotic stable,

$a_{1}\|x\|^{b} \leqslant V(t, x(t)) \leqslant a_{2}\|x\|$

$\dot{V}(t, x(t)) \leqslant-a_{3}\|x\|$

where $a_{1}, a_{2}, a_{3}$ and $b$ are positive constants and $\|\cdot\|$ denotes an arbitrary norm.

Lemma 4 ([24]). If $x=0$ is an equilibrium point of the fractional-order system $D^{q}=f(x, t)$, there exists a Lyapunov function $V(t, x(t))$ and class- $K$ functions $\mu_{i}(i=1,2,3)$ satisfying the following conditions, and the system is asymptotic stable,

$\mu_{1}\|x\| \leqslant V(t, x(t)) \leqslant \mu_{2}\|x\|$

${ }_{t_{0}}^{C} D_{t}^{q} V(t, x(t)) \leqslant-\mu_{3}\|x\|$

where $q \in(0,1]$.

Theorem 1. If the sliding surface is designed as Eq. (17), the sliding mode dynamic system in Eq. (21) is stable and its state trajectories will converge to zero.

Proof. The Lyapunov function is selected as,

$V(t)=|x|$

and its fractional-order derivative is described as,

$$
\begin{aligned}
D^{q} V(t) & =\operatorname{sign}(x) D^{q} x \\
& =\operatorname{sign}(x)\left(-k_{1} x-k_{2}|x|^{\sigma} \operatorname{sat}(x)\right) \\
& =-k_{1}|x|-k_{2}|x|^{\sigma} \operatorname{sign}(x) \times \operatorname{sat}(x)
\end{aligned}
$$

Based on the definition of sat(.) function in Eq. (18), the following equations are obtained,

$\operatorname{sat}(s) \operatorname{sign}(s)=\operatorname{sign}(s / k) \operatorname{sign}(s)=1 \quad(|s|>k)$

$\operatorname{sat}(s) \operatorname{sign}(s)=s / k \times \operatorname{sign}(s)=|s| / k>0 \quad(|s| \leqslant k)$

Based on Eqs. (25)-(27), it yields,

$D^{q} x=-k_{1}|x|-k_{2}|x|^{\sigma} \operatorname{sign}(x) \times \operatorname{sat}(x) \leqslant-k_{1}|x|<0$

This completes the proof. Based on Lemma 4, the sliding-mode dynamic system in Eq. (21) is stable and its state trajectories will converge to zero when the sliding surface is designed as Eq. (17),

Based on Theorem 1, the appropriate sliding surface has been formed. Then, a controller $u(t)$ which can ensure the state trajectories reach the sliding surface $s(t)=0$ and make the system Eq. (16) remain on it is specified.

The equivalent control law in Eq. (29) can be obtained by taking Eq. (21) into Eq. (16).

$u_{e q}(t)=-\left(k_{1} x+k_{2}|x|^{\sigma} \operatorname{sat}(x)-f(x, t)-\Delta f(x, t)-d(t)\right)$

This equivalent control can be considered as the mean value of the discontinuous control on the sliding surface. In order to satisfy the sliding condition in the presence of uncertain terms and external disturbances, the discontinuous reaching law is assumed as follows,

$u_{r}(t)=-k_{3} s-k_{4} \operatorname{sat}(s)-k_{5} \operatorname{sign}(s)$

where $k_{3}, k_{4}, k_{5}>0$.

Then, the sliding mode control law can be described below,

$$
\begin{aligned}
u(t) & =u_{e q}+u_{r}=-\left(f(x)+k_{1} x+k_{2}|x|^{\sigma} \operatorname{sat}(x)\right)-k_{3} s \\
& -(\Delta f(x, t)+d(t))-k_{4} \operatorname{sat}(s)-k_{5} \operatorname{sign}(s)
\end{aligned}
$$

The controller in Eq. (31) is not feasible as the uncertain terms and external disturbances are unknown (i.e. $\Delta f(x, t), d(t)$ are unknown). Hence, an implementable controller can be designed in Eq. (32), as follows,

$$
\begin{aligned}
u(t) & =u_{e q}+u_{r}=-\left(f(x)+k_{1} x+k_{2}|x|^{\sigma} \operatorname{sat}(x)\right)-k_{3} s \\
& -\operatorname{sign}(s)\left(\xi_{1}+\xi_{2}\right)-k_{4} \operatorname{sat}(s)-k_{5} \operatorname{sign}(s)
\end{aligned}
$$

where $\xi_{1}, \xi_{2}$ are two constants, and $\xi_{1}, \xi_{2}>0$.

Theorem 2. Considering the FOESERS in Eq. (9) with the conditions $|\Delta f(x, t)| \leqslant \xi_{1},|d(t)| \leqslant \xi_{2}$ and the control law is designed as Eq. (32). The state trajectories of the FOESERS will converge to the sliding surface $s(t)=0$ and remain on it in a finite time.

Proof. The Lyapunov function can be chosen as $V(t)=\frac{1}{2} s^{2}$ and its time derivative can be described as follows,

$\dot{V}(t)=s \dot{s}$

According to Eq. (20), it obtains,

$\dot{V}(t)=s\left(D^{q} x+\left(k_{1} x+k_{2}|x|^{\sigma} \operatorname{sat}(x)\right)\right)$

From Eq. (16), Eq. (34) can be rewritten as,

$$
\begin{aligned}
\dot{V}(t) & =s\left(f(x)+\Delta f(x)+d(t)+u(t)+\left(k_{1} x+k_{2}|x|^{\sigma} \operatorname{sat}(x)\right)\right) \\
& =s\left(f(x)+u(t)+\left(k_{1} x+k_{2}|x|^{\sigma} \operatorname{sat}(x)\right)\right)+s(\Delta f(x, t)+d(t))
\end{aligned}
$$

Based on the conditions $|\Delta f(x, t)| \leqslant \xi_{1}$, and $|d(t)| \leqslant \xi_{2}$, there is,

$$
\begin{aligned}
\dot{V}(t) & =s\left(f(x)+u(t)+\left(k_{1} x+k_{2}|x|^{\sigma} \operatorname{sat}(x)\right)\right)+\operatorname{sign}(s)(\Delta f(x, t)+d(t)) \\
& \leqslant s\left(f(x)+u(t)+\left(k_{1} x+k_{2}|x|^{\sigma} \operatorname{sat}(x)\right)\right)+|s|\left(\xi_{1}+\xi_{2}\right)
\end{aligned}
$$

Eq. (32) is substituted into Eq. (36), one yields,

$$
\begin{aligned}
\dot{V}(t) \leqslant & s\left(f(x)-\left(f(x)+k_{1} x+k_{2}|x|^{\sigma} \operatorname{sat}(x)+k_{3} s+\operatorname{sign}(s)\left(\xi_{1}+\xi_{2}\right)\right.\right. \\
& \left.+k_{4} \operatorname{sat}(s)+k_{5} \operatorname{sign}(s)\right) \\
+ & \left.\left(k_{1} x+k_{2}|x|^{\sigma} \operatorname{sat}(x)\right)\right)+|s|\left(\xi_{1}+\xi_{2}\right) \\
\leqslant & s\left(-k_{3} s-k_{4} \operatorname{sat}(s)-k_{5} \operatorname{sign}(s)\right)-|s|\left(\xi_{1}+\xi_{2}\right)+|s|\left(\xi_{1}+\xi_{2}\right) \\
= & s\left(-k_{3} s-k_{4} \operatorname{sat}(s)-k_{5} \operatorname{sign}(s)\right)
\end{aligned}
$$

Due to $s \times \operatorname{sign}(s)=|s|$, one has,

$$
\begin{aligned}
\dot{V}(t) & \leqslant s\left(-k_{3} s-k_{4} \operatorname{sat}(s)-k_{5} \operatorname{sign}(s)\right) \\
& \leqslant-k_{3} s^{2}-k_{4} s \times \operatorname{sat}(s)-k_{5}|s|
\end{aligned}
$$

Based on the definition of the saturation function sat $(\cdot)$, there is,

$x \operatorname{sat}(x)=x \operatorname{sign}(x / k) \quad(|s|>k)$

$x \operatorname{sat}(x)=x^{2} / k \quad(|s| \leqslant k)$

Due to $x \times \operatorname{sign}(x)=|x|$, one gets,

$x \operatorname{sat}(x)=k \frac{x}{k} \operatorname{sign}(x / k)=k \times|x / k|=|x| \quad(k>0)$

It follows Eqs. (39)-(41), it obtains,

$$
\begin{aligned}
\dot{V}(t) & \leqslant-k_{3} s^{2}-k_{4} s \times \operatorname{sat}(s)-k_{5}|s| \\
& \leqslant-k_{3} s^{2}-k_{5}|s|<0
\end{aligned}
$$

According to Lemma 3, the state trajectories of the uncertain FOESER in Eq. (9) will converge to $s(t)=0$, and the state vector $x(t)$ is asymptotically stable. Then, in order to prove that the stable motion occurs within a finite time, the reaching time $T$ can be obtained as follows,

Due to $V(t)=s^{2} / 2$, Eq. (42) can be written as,

$$
\begin{gathered}
\dot{V} \leqslant-\sqrt{2} k_{5} V^{1 / 2}-2 k_{3} V \\
\text { If } r=\min \left(\sqrt{2} k_{5}, 2 k_{3}\right) \text {, then, }
\end{gathered}
$$

$\dot{V} \leqslant-r\left(V^{1 / 2}+2 V\right)$

Hence, Eq. (44) can be written as,

$d t \leqslant \frac{-d V}{r\left(V^{0.5}+V\right)} \leqslant \frac{-V^{-0.5}}{r\left(V^{0.5}+1\right)} d V=\frac{-d V^{0.5}}{r\left(V^{0.5}+1\right)}$ 
Eq. (45) is taken the integral of both sides from 0 to the reaching time $t_{r i}$ and the $V\left(t_{r i}\right)$ is set as $V\left(t_{r i}\right)=0$, one obtains,

$t_{r i} \leqslant-\frac{1}{r} \int_{V(0)}^{V\left(t_{r i}\right)} \frac{d V^{0.5}}{\left(V^{0.5}+1\right)}=\frac{1}{r} \ln \left(V(0)^{0.5}+1\right)$

Consequently, $t_{r i}$ can be obtained as follows,

$t_{r i} \leqslant \frac{1}{r} \ln \left(\frac{1}{\sqrt{2}}|s(0)|+1\right)$

It implies that the state trajectories of uncertain FOESERS (9) with the conditions $|\Delta f(x, t)| \leqslant \xi_{1},|d(t)| \leqslant \xi_{2}$ will converge to the sliding surface $s(t)=0$ in a finite time $T=t_{r i}=\frac{1}{r} \ln \left(\frac{1}{\sqrt{2}}|s(0)|+1\right)$ under the control law in Eq. (32).

\section{Numerical simulations}

In order to validate the robustness, efficiency, feasibility, and applicability of the proposed fractional-order controller in stabilizing the uncertain FOESERS in a given time, the FOESERS with different fractional orders and different uncertain terms and external disturbances is presented as follows,

$\left\{\begin{array}{l}D^{q_{1} x_{1}}=\alpha_{1} x_{1}\left(\frac{x_{2}}{N}-1\right)-\alpha_{2} x_{2}+\alpha_{3} x_{3}+\Delta f_{1}+d_{1}(t)+u_{1}(t) \\ D^{q_{2}} x_{2}=-\beta_{1} x_{1}+\beta_{2} x_{2}\left(1-\frac{x_{2}}{K}\right)+\beta_{3} x_{3}\left(1-\frac{x_{3}}{L}\right)-\delta_{4} x_{4}+\Delta f_{2}+d_{2}(t)+u_{2}(t) \\ D^{q_{3}} x_{3}=\gamma_{1} x_{1}\left(\frac{x_{1}}{M}-1\right)-\gamma_{2} x_{2}-\gamma_{3} x_{3}+\gamma_{4}\left(\frac{x_{4}}{E}-1\right)+\Delta f_{3}+d_{3}(t)+u_{3}(t) \\ D^{q_{4}} x_{4}=\delta_{1} x_{2}+\delta_{2} x_{3}\left(\frac{x_{3}}{C}-1\right)-\delta_{3} x_{4}+\Delta f_{4}+d_{4}(t)+u_{4}(t)\end{array}\right.$

The uncertain terms and external disturbances of FOESERS are chosen as follows [30],

$\Delta f_{1}(X, t)+d_{1}(t)=0.1 \sin (t) x_{1}+0.1 \cos (t)$

$\Delta f_{2}(X, t)+d_{2}(t)=-0.1 \cos (t) x_{2}+0.1 \cos (t)$

$\Delta f_{3}(X, t)+d_{3}(t)=-0.1 \sin (3 t) x_{3}-0.1 \cos (2 t)$

$\Delta f_{4}(X, t)+d_{4}(t)=0.1 \cos (5 t) x_{4}+0.1 \sin (t)$

The initial conditions of the FOESERS can be predetermined as the settings in [18]: $x_{1}(0)=0.015, x_{2}(0)=0.785, x_{3}(0)=1.83, x_{4}(0)=0.01$. According to Eqs. (17) and (32), the parameters are selected as: $k_{1}=10, k_{2}=2, \sigma=0.2, k_{3}=4, k_{4}=1, k_{5}=0.01, \xi_{1}=0.1, \xi_{2}=0.1$, and the sliding surface and control law are designed as follows,

$$
\begin{aligned}
s_{i}(t) & =D^{q_{i}-1} x+D^{-1}\left(10 x_{i}+2 \times\left|x_{i}\right|^{\sigma} \operatorname{sat}\left(x_{i}\right)\right) \\
u_{i}(t) & =-\left(f_{i}(x)+k_{1} x_{i}+k_{2}\left|x_{i}\right|^{\sigma} \operatorname{sat}\left(x_{i}\right)\right)-k_{3} s_{i} \\
& -\operatorname{sign}(s)\left(\xi_{1}+\xi_{2}\right)-k_{4} \operatorname{sat}\left(s_{i}\right)-k_{5} \operatorname{sign}\left(s_{i}\right) \quad i=1,2,3,4
\end{aligned}
$$

With the proposed sliding surface in Eq. (50) and robust control scheme in Eq. (51), the state trajectories of the uncertain commensurate-order FOESERS with $q=0.95$ is shown in Fig. 7. Compared with the state trajectories of the uncertain commensurate-order FOESERS with fractional-order $q=0.99$ which is shown in Fig. 8, the proposed fractional-order controller is feasible and robust for the FOESERS with different fractional orders. For the uncertain incommensurate-order FOESERS with $\left(q_{1}, q_{2}, q_{3}, q_{4}\right)=(0.92,0.94,0.96,0.98)$, the state trajectories of the uncertain FOESERS are shown in Fig. 9. The proposed control method is not only suitable for the uncertain FOESERS with $0<q<1$, but also is suitable for the uncertain ESERS with $q=1.0$. (i.e. Integerorder model of ESERS). The state trajectories of uncertain FOESERS with $q=1.0$ are illustrated in Fig. 10. It can be found that the uncertain FOESERS with different fractional orders is asymptotic stable with the proposed sliding mode control, and the state trajectories can converge to zero promptly. Besides, the stabilized time under the proposed controller is within $0.5 \mathrm{~s}$. According to Eq. (47), the calculated finite

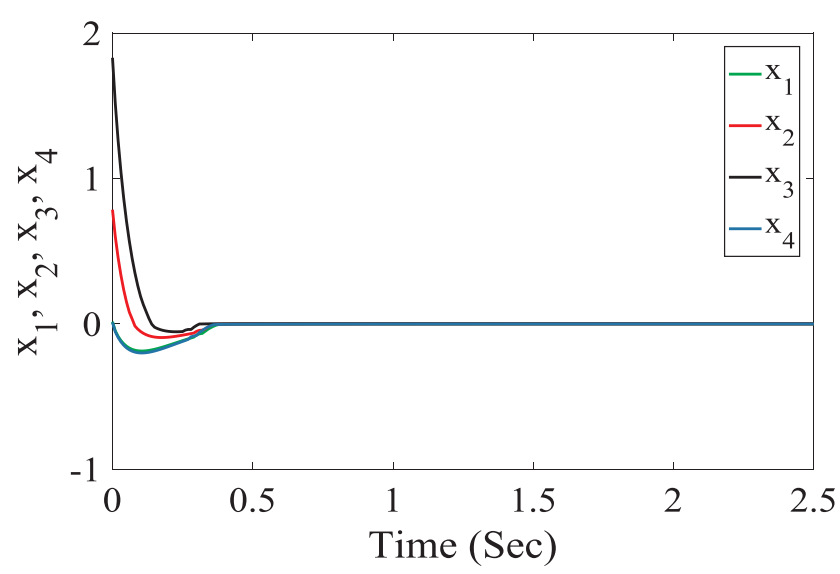

Fig. 7. State trajectories in the commensurate-or der FOESERS with $q=0.95$.

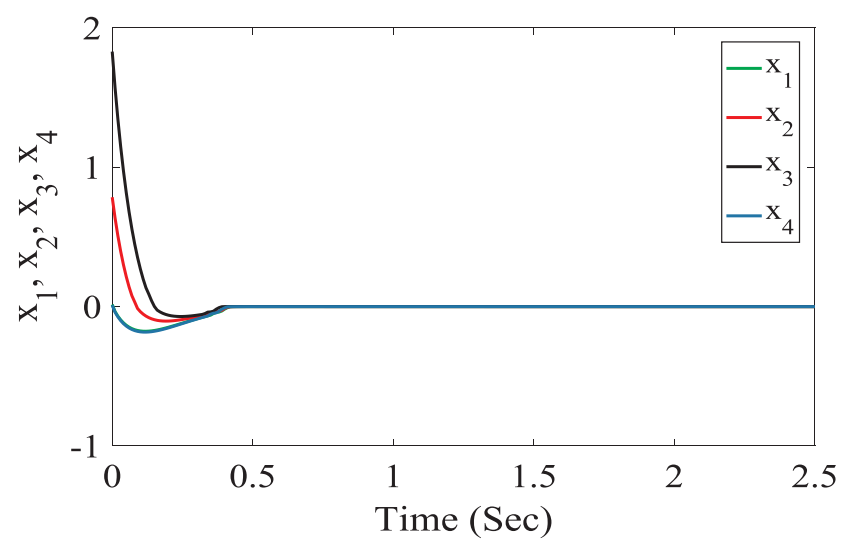

Fig. 8. State trajectories in the commensurate-or der FOESERS with $q=0.99$.

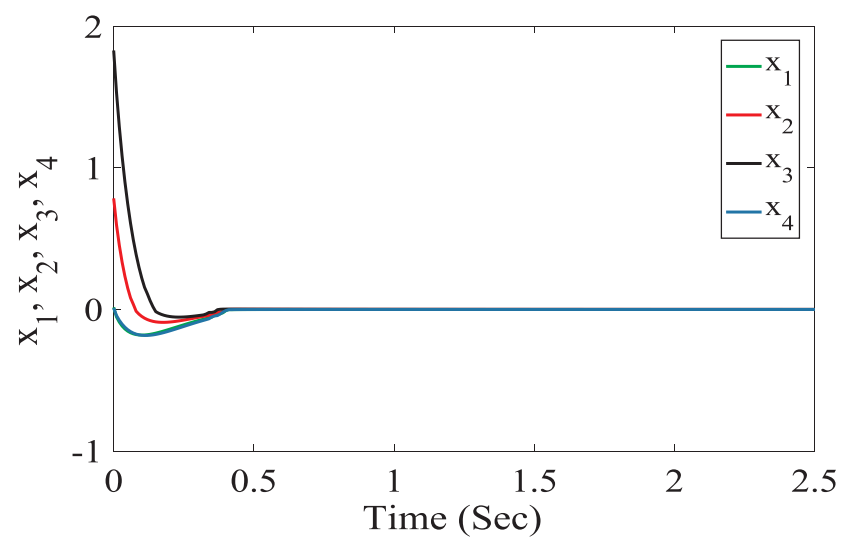

Fig. 9. State trajectories in the incommensurate-order FOESERS with $\left(q_{1}, q_{2}, q_{3}, q_{4}\right)=(0.92,0.94,0.96,0.98)$.

time is $t_{r i}=0.95 \mathrm{~s}$ with initial value $s(0)=[1,1,1,1]^{T}$, and it is shown that the nonlinear vibration of the uncertain FOESERS is efficiently suppressed in a finite time.

In order to confirm the robustness of the proposed controller, different uncertain terms and external disturbances of the FOESER are set as follows [27],

$\Delta f_{1}(X, t)+d_{1}(t)=0.5 \sin (t) x_{1}+0.2 \cos (t)$

$\Delta f_{2}(X, t)+d_{2}(t)=-0.5 \cos (t) x_{2}+0.2 \cos (t)$

$\Delta f_{3}(X, t)+d_{3}(t)=-0.5 \sin (3 t) x_{3}-0.2 \cos (2 t)$

$\Delta f_{4}(X, t)+d_{4}(t)=0.5 \cos (5 t) x_{4}+0.2 \sin (t)$

The initial conditions of the FOESERS can be predetermined as the 


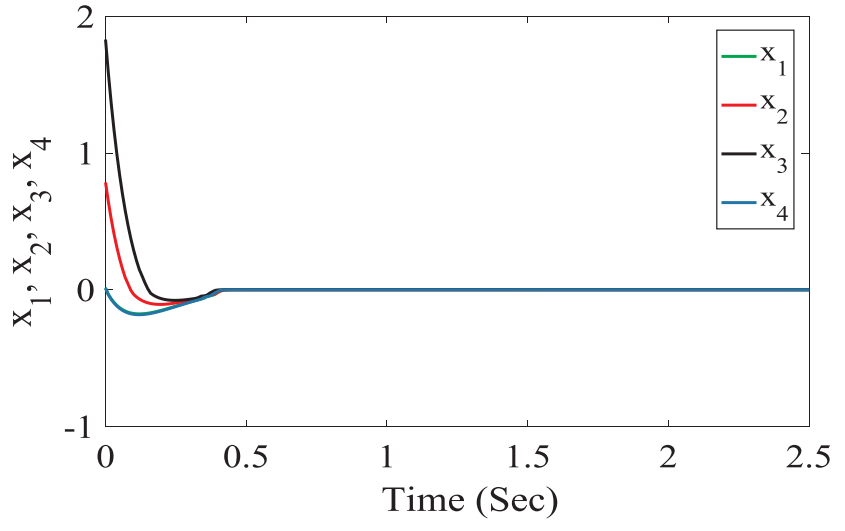

Fig. 10. State trajectories in the commensurate-order FOESERS with $q=1.0$.

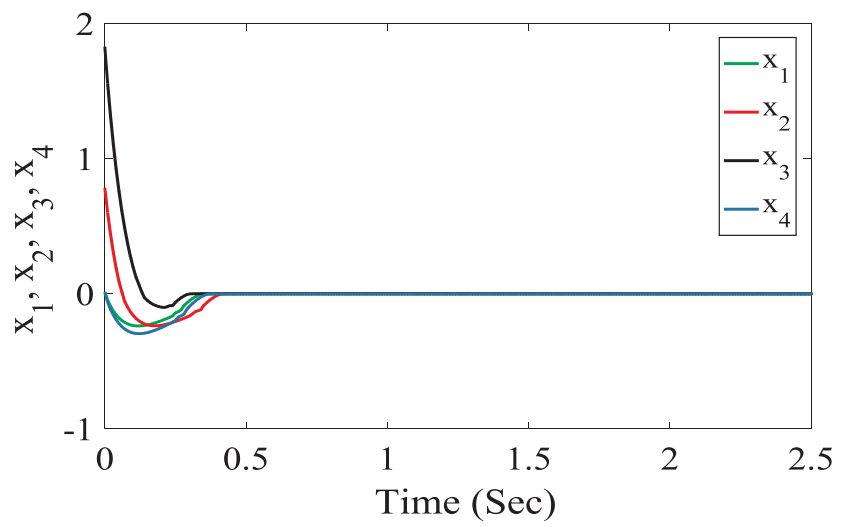

Fig. 11. State trajectories in the commensurate-or der FOESERS with $q=0.99$.

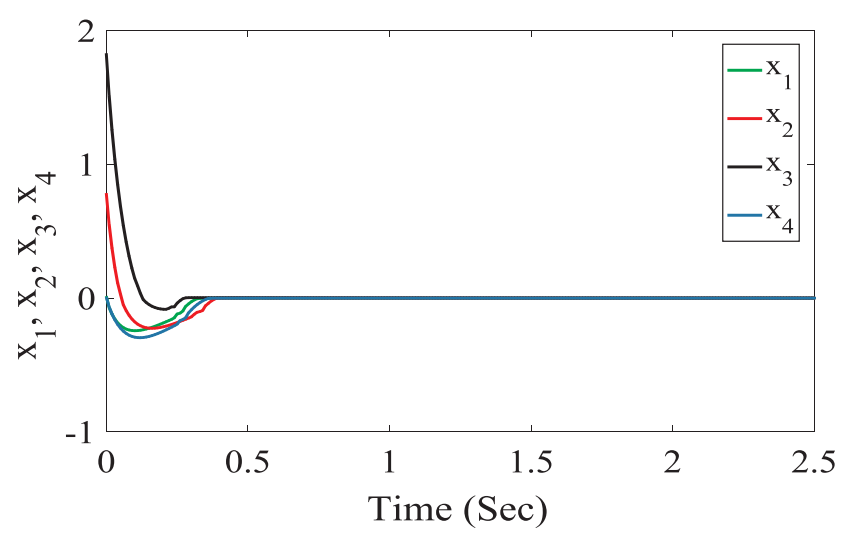

Fig. 12. State trajectories in the incommensurate-order FOESERS with $\left(q_{1}, q_{2}, q_{3}, q_{4}\right)=(0.92,0.94,0.96,0.98)$.

settings in [18]: $x_{1}(0)=0.015, x_{2}(0)=0.785, x_{3}(0)=1.83, x_{4}(0)=0.01$. Based on Eqs. (17) and (32), the parameters are selected as: $k_{1}=10, k_{2}=2, \sigma=0.2, k_{3}=4, k_{4}=1, k_{5}=0.4, \xi_{1}=0.5, \xi_{2}=0.2$, and the sliding surface and control law are given in Eqs. (50) and (51), respectively. With the proposed robust control scheme under system uncertain terms and external disturbances in Eq. (52), the state trajectories of the uncertain commensurate-order FOESERS, the uncertain incommensurate-order FOESERS, and the integer-order model of ESERS are shown in Figs. 11, 12 and 13, respectively. It is shown from the results that the nonlinear vibration of the uncertain FOESERS is efficiently suppressed in a finite time to confirm the robustness of the proposed controller.

In addition, when the initial values of the sliding mode surface are given, the stabilized time is only related to $r$ according to Eq. (47). Due

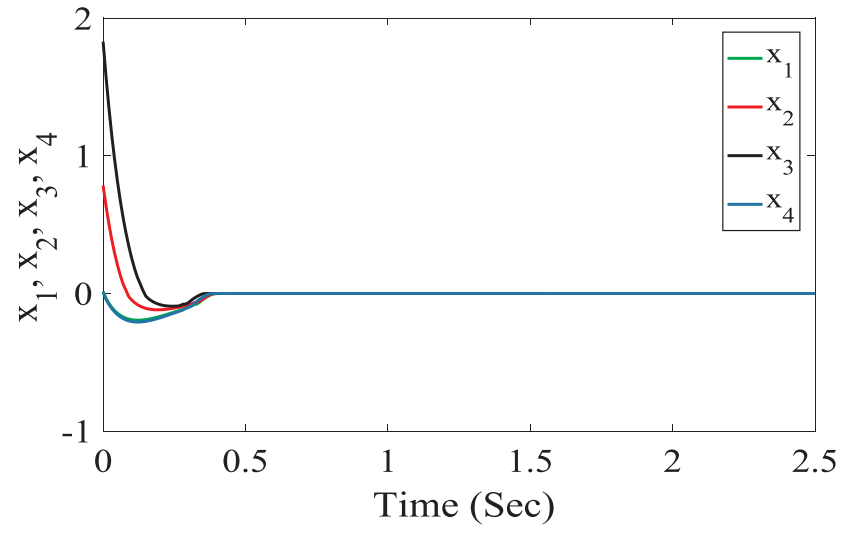

Fig. 13. State trajectories in the integer-order model of ESERS.

to $r=\min \left(\sqrt{2} k_{5}, 2 k_{3}\right)$, the stabilized time is related to $k_{3}$ and $k_{5}$. In order to make the uncertain FOESERS stable in the minimum time, it is necessary to select the suitable values of $k_{3}$ and $k_{5}$, and $k_{5}$ is the dominated parameter as the value of $k_{3}$ is much greater than $k_{5}$. Here, $k_{5}$ is set to be 0.5 to test its effects on the control performance. With the proposed robust control scheme under system uncertain terms and external disturbances in Eq. (52), the state trajectories of the uncertain commensurate-order FOESERS, the uncertain incommensurate-order FOESERS, and the integer- order model of ESERS are shown in Figs. 14, 15 , and 16, respectively. It can be found that the state trajectories of the uncertain FOESERS exists chattering phenomenon when $k_{5}=0.5$, while the uncertain FOESERS is stable when $0<k_{5} \leqslant 0.4$.

\section{Conclusions}

In this paper, the fractional-order modeling of a four-dimensional dynamic evolution ESERS is investigated, and then a sliding mode robust control method is proposed for FOESERS to cope with the uncertainties and external disturbances. The main conclusions of the proposed methodology are summarized as follows: (1) The Caputo fractional-order calculus can be used to represent the evolutionary dynamics of ESERS, and the investigations on complex behaviours of the proposed FOESERS through the dissipative nature, equilibrium points, and instability region indicate the nonlinear chaotic and unstable phenomena on energy conservation, carbon emissions, economic growth, and renewable energy development; (2) Based on the Lyapunov stability theorems and sliding mode control theory, the proposed robust control method can ensure that the sliding motion occurs in a finite time for stabilization and suppression for nonlinear vibration of FOESERS under uncertainties and external disturbances. Numerical simulations on the commensurate-order FOESERS, the incommensurateorder FOESERS and the integer-order model of ESERS considering

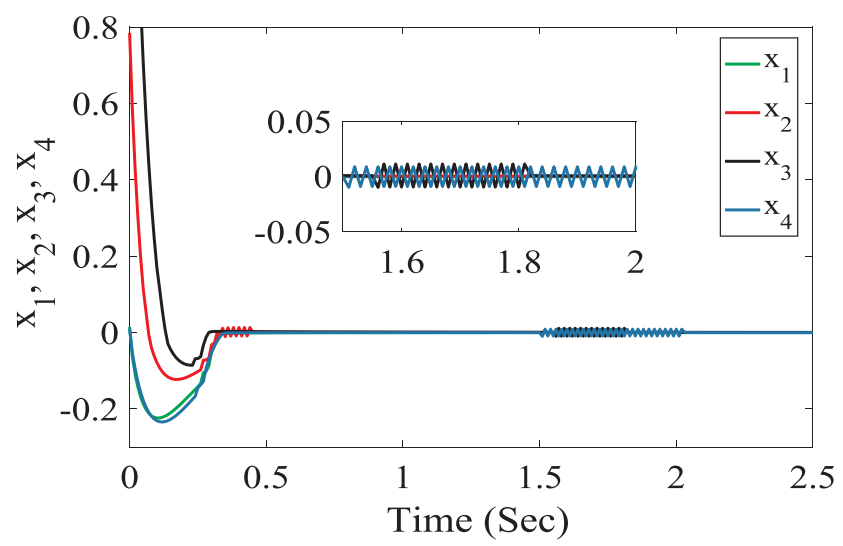

Fig. 14. State trajectories in the commensurate-or der FOESERS with $q=0.99$. 


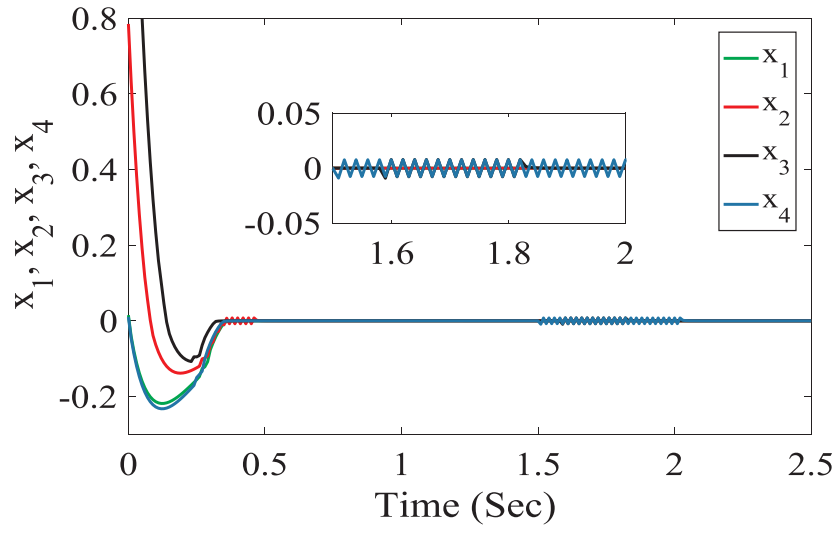

Fig. 15. State trajectories in the incommensurate-order FOESERS with $\left(q_{1}, q_{2}, q_{3}, q_{4}\right)=(0.92,0.94,0.96,0.98)$.

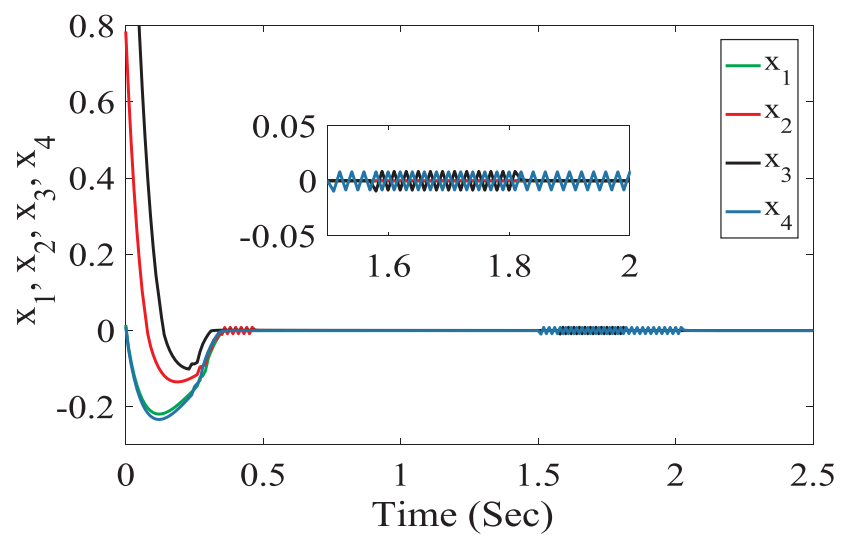

Fig. 16. State trajectories in the integer-order model of ESERS.

different uncertainty and external disturbances have been implemented, and the comparative results confirms the effectiveness and robustness of the proposed scheme.

\section{Acknowledgment}

The authors gratefully acknowledge the support of the National Natural Science Foundation of China (51507056), Hunan Strategic Industries Scientific and Technological Project under Grant 2017GK4028, and the Hunan Natural Science Foundation of China (2017JJ3019).

\section{References}

[1] Sun M, Wang XF, Chen Y, Tian LX. Energy resources demand-supply system analysis and empirical research based on non-linear approach. Energy 2011;36:5460-5.

[2] Niu SW, Ding YX, Niu YZ, Li YX, Luo GH. Economic growth, energy conservation and emissions reduction: a comparative analysis based on panel data for 8 AsianPacific countries. Energy Policy 2011;39:2121-31.

[3] Chen WD, Geng WX. Fossil energy saving and $\mathrm{CO}_{2}$ emissions reduction performance, and dynamic change in performance considering renewable energy input. Energy 2017;120:283-92.

[4] Clancy JM, Gaffney F, Deane JP, Curtis J, Gallachóir BPÓ. Fossil fuel and $\mathrm{CO}_{2}$ emissions savings on a high renewable electricity system - a single year case study for Ireland. Energy Policy 2015;83:151-64.

[5] Qi TY, Zhang XL, Karplus VJ. The energy and $\mathrm{CO}_{2}$ emissions impact of renewable energy development in China. Energy Policy 2014;68:60-9.

[6] Ozturk I, Acaravci A. $\mathrm{CO}_{2}$ emissions, energy consumption and economic growth in
Turkey. Renew Sustain Energy Rev 2010;14:3220-5.

[7] Habib MA, Hasanuzzaman M, Salman A, Mehadi MR. Energy consumption, energy saving and emission reduction of a garment industrial building in Bangladesh. Energy 2016;112:91-100.

[8] National Bureau of Statistics of China. China Statistical Yearbook (2006-2016). Beijing: China Statistics Press; 2016.

[9] National Bureau of Statistics of China. China Energy Statistical Yearbook 2016. Beijing: China Statistics Press; 2016.

[10] Mittal S, Dai H, Fujimori S, Masui T. Bridging greenhouse gas emissions and renewable energy deployment target: comparative assessment of China and India. Appl Energy 2016;166:301-13.

[11] Gao CW, Li Y. Evolution of China's power dispatch principle and the renewable energy saving power dispatch policy. Energy Policy 2010;38:7346-57.

[12] Wang Q, Li R, Kazmerski L. Journey to burning half of global coal: trajectory and drivers of China's coal use. Renew Sustain Energy Rev 2016;58:341-6.

[13] Wang CH, Zhao D, Tsutsumi A, Your S. Sustainable energy technologies for energy saving and carbon emission reduction. Appl Energy 2017;194:223-4.

[14] Fang GC, Tian LX, Fu M, Sun M. The impacts of carbon tax on energy intensity and economic growth - a dynamic evolution analysis on the case of China. Appl Energy 2013;110:17-28.

[15] Wang Q, Su B, Sun J, Zhou P, Zhou D. Measurement and decomposition of energysaving and emissions reduction performance in Chinese cities. Appl Energy 2015;151:85-92.

[16] Saidur R, Akash B. A review on boilers energy use, energy savings, and emissions reductions. Renew Sustain Energy Rev 2017;79:970-83.

[17] Fang GC, Tian LX, Sun M, Fu M. Analysis and application of a novel three-dimensional energy-saving and emission-reduction dynamic evolution system. Energy 2012;40:291-9.

[18] Wang MG, Xu H. A novel four-dimensional energy-saving and emission-reduction system and its linear feedback control. J Appl Math 2012;4:401-30.

[19] Fang GC, Tian L, Fu M, Sun M, Du RJ, Lu LX, et al. The effect of energy construction adjustment on the dynamical evolution of energy-saving and emission-reduction system in China. Appl Energy 2017;196:180-9.

[20] Fang GC, Tian LX, Fu M, Sun M, Du RJ, Lu LX. Investigating carbon tax pilot in YRD urban agglomerations-analysis of a novel ESER system with carbon tax constraints and its application. Appl Energy 2017;194:635-47.

[21] Fu M, Hua AQ, Fan XH, Fang GC. Coordinated development of energy-saving and emission-reduction evolution systems in the Yangtze River delta. Int J Global Energy Issues 2016;39:35-47.

[22] Aguiar B, González T, Bernal M. A way to exploit the factional stability domain for robust chaos suppression and synchronization via LMIs. IEEE Trans Autom Control 2016;61:2796-807.

[23] Shotorbani AM, Ghassem-Zadeh S, Mohammadi-Ivatloo B, Hosseini SH. A distributed secondary scheme with terminal sliding mode controller for energy storages in an islanded microgrid. Int J Electr Power Energy Syst 2017;93:352-64.

[24] Huang SH, Wang B. Stability and stabilization of a class of fractional-order nonlinear systems for $0<\alpha<2$. Nonlinear Dyn 2017;88:973-84.

[25] Viola L, Lloyd S. Dynamical suppression of decoherence in two-state quantum systems. Phys Rev A 2012;58:2733-44.

[26] Deng ZC, Xu YL, Gu W, Fei ZY. Finite-time convergence robust control of battery energy storage system to mitigate wind power fluctuations. Int J Electr Power Energy Syst 2017;91:144-54.

[27] Aghababa MP. Fractional modeling and control of a complex nonlinear energy supply-demand system. Complexity 2015;20:74-86.

[28] Aghababa MP, Haghighi AR, Roohi M. Stabilisation of unknown fractional-order chaotic systems: an adaptive switching control strategy with application to power systems. IET Gener Transm Distrib 2015;9:1883-93.

[29] Wang X, Wei X, Meng Y. Experiment on grid-connection process of wind turbines in fractional frequency find power system. IEEE Trans Energy Convers 2015;30:22-31.

[30] Sondhi S, Hote YV. Fractional order PID controller for perturbed load frequency control using Kharitonov's theorem. Int J Electr Power Energy Syst 2016:78:884-96.

[31] Ghasemi S, Tabesh A, Askari-Marnani J. Application of fractional calculus theory to robust controller design for wind turbine generators. IEEE Trans Energy Convers 2014;29:780-7.

[32] N'Doye I, Darouach M, Voos H. Observer-based approach for fractional-order chaotic synchronization and communication. IEEE J Emerg Sel Top Circ Syst 2013;3:442-50.

[33] Borah M, Roy BK. Dynamics of the fractional-order chaotic PMSG, its stabilisation using predictive control and circuit validation. IET Electr Power Appl 2017;11:707-16.

[34] Mohanty A, Viswavandya M, Mohanty S. An optimised FOPID controller for dynamic voltage stability and reactive power management in a stand-alone micro grid. Int J Electr Power Energy Syst 2016;78:524-36.

[35] Wang B, Ding JL, Wu FJ, Zhu DL. Robust finite-time control of fractional-order nonlinear systems via frequency distributed model. Nonlinear Dyn 2016;85:2133-42. 